VET BRIEF

ZOOS' PRINT JOURNAL 22(6): 2734

\section{Management of gun-shot wounds in a Sloth Bear} Melursus ursinus

\author{
I. Nath ${ }^{1}$, T.K. Pattanaik ${ }^{2}$, N. Sahoo ${ }^{3}$, V.S.C. Bose ${ }^{4}$, \\ J.K. Das ${ }^{5}$, Alok Das ${ }^{6}$ and Arun Kumar Mishra ${ }^{7}$
}

${ }^{1,2}$ Associate Professor, ${ }^{4}$ Professor, ${ }^{5}$ Assistant Professor, Department of Surgery, ${ }^{3}$ Associate Professor, Department of Medicine, Orissa Veterinary College, Bhubaneswar, Orissa 751003 , India; ${ }^{6}$ Veterinary Officer, ${ }^{7}$ Assistant Director, Nandankanan Zoological Park, Orissa, India

Email: ${ }^{1}$ indravet@yahoo.co.in

plus web supplement of 1 page

Gun-shot wounds should be considered serious until proved otherwise because of the tremendous kinetic energies and penetration effects potentially present (Crane, 1985). The present paper describes management of gun-shot wounds in a Sloth Bear (Melursus ursinus).

A captive male Sloth Bear aged about $5 y r$ owned by Amsena a nongovernment organization was inflicted with bullet injuries from the security guard of the district collector of Nuapara on 25.vi.2006. While the collector was inspecting the NGO the bear escaped from the cage and attacked him. The security person immediately fired four rounds of bullets towards the bear to save the collector. The injured bear was presented to the surgery department, Orissa Veterinary College in a squeeze cage carried on a truck on 6.vii.2006 for thorough examination and treatment. The animal was anaesthetized using a mixture of $1.3 \mathrm{mg}$ of atropine sulphate, $300 \mathrm{mg}$ of xylazine hydro-chloride and 500mg of ketamine hydrochloride as single bolus intramuscular injection (Image $\left.1^{\mathrm{w}}\right)$. The bear became recumbent within $5 \mathrm{~min}$. Then it was removed from the cage (Image $2^{\mathrm{w}}$ ) and transported to the x-ray room by a wheeled trolley. The temperature, pulse, respiration and heart rate were $100.4^{\circ} \mathrm{F}$, $76 / \mathrm{min}, 12 / \mathrm{min}$ and $80 / \mathrm{min}$, respectively. The values of haemoglobin, total leucocytes count, neutrophil, eosinophil, lymphocyte and monocyte were recorded to be $8 \mathrm{~g} \%, 5,600 / \mathrm{cu} \mathrm{mm}, 60,4,29$ and 7 . The biochemical parameters GPT, GOT and BUN were $17 \mathrm{U} / \mathrm{L}, 72 \mathrm{U} / \mathrm{L}$ and $24.2 \mathrm{mg} / \mathrm{dl}$. Radiographs were taken in lateral and ventro-dorsal views and processed. No bullets could be located in the leg or thigh regions. Complete examination of body revealed three wounds. A bullet entry wound of $1 \mathrm{~cm}$ diameter on the left lateral region below the level of ischeal arch and the exit wound of about $2 \mathrm{~cm}$ diameter was located on the medial aspect of the thigh (Image $3^{w}$ ). The tongue was injured with free portion nearly half the width on the left side injuring the lateral aspect of the lip also nearer to the commissure (Image $4^{\mathrm{w}}$ ). The wound was healing. The injury of the lip was about one-half inch at an oblique angle. There was a bruise of about one-half inch, might be due to bullet injury on the right side of the neck (Image $5^{\mathrm{w}}$ ); no bullet had penetrated into the neck. The wounds on the tongue, lip and neck regions were treated with Terramycin liquid as they were superficial. The wounds at the left hind limb were cleaned and exudates were collected into a sterile syringe for antibiotic sensitivity test. These wounds were also thoroughly cleaned and irrigated with Terramycin liquid after shaving the area. There was no trace of suppuration in the neck though it was 10 days old. The metal detector also did not indicate the presence of any metallic objects in the body (Image $6^{\mathrm{w}}$ ). One bottle each of DNS 5\%, D5 and RL were administered intravenously throughout the treatment period. The bear was revived with $20 \mathrm{mg}$ of yohimbine hydrochloride after being placed back in the cage. It recovered within 15 minutes and returned back to the zoo by truck. Dressing of the wounds with terramycine liquid and fly repellant continued for three days. Thereafter, $1 \mathrm{~g}$ of parenteral cefotaxime and local dressing with cephalexine powder was done according to sensitivity test for five days. The bear recovered uneventfully. Though serious the gun-shot wounds in the present case had not penetrated deeper and the

w See Images $1-6^{\mathrm{w}}$ in the web supplement at www.zoosprint.org vital structures as evidenced from the radiograph. The bear was active on the day it arrived to the veterinary hospital for surgery. Cleaning of entry and exit wounds and parenteral sensitive antibiotic resulted in healing of the gun-shot wounds as suggested by Bright and Probst (1985) in small animals.

\section{References}

Bright, R.M. \& C.W. Probst (1985). Management of superficial skin wounds. In: Slatter, D. (Ed.). Textbook of Small Animal Surgery Vol. I. $1^{\text {st }}$ Edition. W.B. Saunders Company, Philadelphia, 439pp.

Crane, S.W. (1985). Epidemiology and mechanism of trauma in companion animals. In: Slatter, D. (Ed.). Textbook of Small Animal Surgery Vol. I. $1^{\text {st }}$ Edition. W.B. Saunders Company, Philadelphia, 439pp.

Acknowledgement: Authors are thankful to the Director, Nandankanan Zoological Park for according permission to do the work.

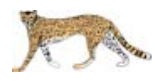

\section{VET BRIEF}

ZOOS' PRINT JOURNAL 22(6): 2734-2735

\section{Dystocia in Barasingha Rucervus duvaucelii}

\section{K. Senthilkumar ${ }^{1}$, K. Devaki ${ }^{2}$ and S. Sathasivam ${ }^{3}$}

${ }^{1,3}$ Veterinary Assistant Surgeon, ${ }^{2}$ Zoo Veterinarian, Arignar Anna Zoological Park, Vandalur, Chennai, Tamil Nadu Email: ${ }^{1}$ drsenthil72@hotmail.com

plus web supplement of 1 page

Dystocia is an occasional complication of parturition in both free ranging and captive exotic artiodactylids. The majority of dystocia cases in the monotocous species is foetal in type and is the outcome of abnormal presentation, position and posture and to excessive size of the foetus. Dystocia in posterior presentation is relatively much more common than dystocia in anterior presentation (Roberts, 2002).

It has to be treated in much the same way as it is in domestic species. The first aim of treatment is to convert it into normal anterior or posterior presentation and having done this hasten delivery by relatively gentle traction (Arthur et al., 1982). Therefore, a case of dystocia of posterior presentation in captive Barasingha (Swamp Deer) Rucervus duvaucelii at the Arignar Anna Zoological Park (AAZP) is communicated.

A pregnant primipara Barasingha at AAZP aged about 4 years and in its first gestation showed symptoms of dystocia after its full term. Zoo authorities reported that the animal was showing symptoms for the past two hours with restlessness, intermittent straining, discharge from the genitalia with protruded hind limbs through the vulva (Image $1^{\mathrm{w}}$ ) with no progression in labour, hence it was suspected that she possessed foetus with mal presentation and or it was a case of foetus-maternal disproportion. Accordingly the animal was darted with $8 \mathrm{mg}$ of valethamate bromide to relax the cervix intramuscularly. The animal was left undisturbed for about 30 minutes and observed. The animal was still straining and the two protruding hind limbs were visible. It was decided to correct the malpresentation of foetus manually.

\section{Clinical Examination and Treatment}

The animal was tranquilized with air gun dart with a combination of $100 \mathrm{mg}$ xylazine and $75 \mathrm{mg}$ ketamine at $11.30 \mathrm{hr}$ on 02.viii.2005. The rectal temperature was $103^{\circ} \mathrm{F}$. On clinical examination - per vaginal examination revealed presence of live foetus with two protruding hind limbs confirming the posterior presentation of foetus. Forced traction was applied in the traction points in the hind limbs, with help of artificial lubrication. Finally, the live foetus was delivered and the foetal membrane was completely removed. The animal was 